\title{
Catalytic properties of nanosized zinc aluminates prepared by green process using Opuntia dilenii haw plant extract
}

\author{
C. Ragupathi a , J. Judith Vijaya a,*, S. Narayanan a, L. John Kennedy b, Seeram Ramakrishna ${ }^{\mathrm{c}}$ \\ ${ }^{a}$ Catalysis and Nanomaterials Research Laboratory, Department of Chemistry, Loyola College, Chennai-34, India \\ ${ }^{\mathrm{b}}$ Materials Division, School of Advanced Sciences, Vellore Institute of Technology University, Chennai Campus, Chennai-127, India \\ 'Centre for Nanofibres and Nanotechnology, National University of Singapore, Singapore
}

\section{A R T I C L E I N F O}

Article history:

Received 6 June 2013

Accepted 16 August 2013

Published 20 October 2013

Keywords:

Green synthesis

Zinc aluminate

Spinel

Microwave

Optical property

\begin{abstract}
A B S T R A C T
Various nanosized zinc aluminate $\left(\mathrm{ZnAl}_{2} \mathrm{O}_{4}\right)$ samples were prepared by a conventional and a microwave method both with and without using Opuntia dilenii haw plant extract, and were characterized by X-ray diffraction (XRD), Fourier transform infrared spectroscopy (FT-IR), high resolution scanning electron microscopy (HRSEM), energy dispersion scanning (EDX), temperature dependent conductance measurements, thermoelectric power measurements, ultraviolet-visible (UV-Vis) diffuse reflectance spectroscopy, and photoluminescence spectroscopy. The formation of a pure $\mathrm{ZnAl}_{2} \mathrm{O}_{4}$ phase was confirmed by XRD and FT-IR. A change in morphology from nanosized plates to nanosized sheets with, respectively, the conventional and microwave heating methods was clearly shown by HRSEM. UV-Vis diffusion reflectance spectroscopy measured the band gaps of $\mathrm{ZnAl}_{2} \mathrm{O}_{4}$ nanosized plates and nanosized sheets as 3.5 and $3.9 \mathrm{eV}$, respectively. The synthesized $\mathrm{ZnAl}_{2} \mathrm{O}_{4}$ was single crystalline and has three photoluminescence emissions at 482,528 , and $540 \mathrm{~nm}$. $\mathrm{ZnAl}_{2} \mathrm{O}_{4}$ nanosized sheets prepared by the microwave method showed higher catalytic activity for the oxidation of benzyl alcohol ( $85 \%$ conversion) than $\mathrm{ZnAl}_{2} \mathrm{O}_{4}$ nanosized plates prepared by the conventional method (60\% conversion).
\end{abstract}

(C) 2013, Dalian Institute of Chemical Physics, Chinese Academy of Sciences. Published by Elsevier B.V. All rights reserved.

\section{Introduction}

Transition metal oxides represent a broad class of materials that have been studied extensively for their interesting catalytic, electronic, and magnetic properties. They have a wide range of applications for their optical properties [1] and are used in solar cells [2]. They are commonly used in semiconductor and sensor technology as well as in heterogeneous catalysis [3-5] Zinc aluminate $\left(\mathrm{ZnAl}_{2} \mathrm{O}_{4}\right)$ with a spinel structure is of interest due to a combination of desirable properties such as high mechanical resistance, high thermal stability, low temperature sinterability, low surface acidity, fast diffusion, and high quantum yields. $\mathrm{ZnAl}_{2} \mathrm{O}_{4}$ is widely used as an electronic, ceramic, catalytic material and is emerging as one of the best wide band gap semiconductor $\left(E_{\mathrm{g}}=3.8 \mathrm{eV}\right)$ for various optoelectronic applications [6-8]. In order to provide materials with the desired physical and chemical properties, the preparation of nano-structured $\mathrm{ZnAl}_{2} \mathrm{O}_{4}$ by different routes has become an essential part of research and development. There are many experimental procedures, including co-precipitation [9], sol-gel [10], hydrothermal [11], and pyrolysis of layered double hydroxide precursors [12], which have been developed for the preparation of $\mathrm{ZnAl}_{2} \mathrm{O}_{4}$. These methods demand expensive materials and also generate toxic organic/inorganic intermediates. They involve laborious synthesis procedures. Nowadays, a restricted category of organic substances, e.g., citric acid, urea,

*Corresponding author. Tel: +91-44-28178333; Fax: +91-44-28175566. E-mail: jjvijayaloyola@yahoo.co.in, jjvijaya78@gmail.com DOI: 10.1016/S1872-2067(12)60682-2 | http://www.sciencedirect.com/science/journal/18722067 | Chin. J. Catal., Vol. 34, No. 10, October 2013 
glycine, oxalyldihydrazide, carbohydrazide, tetraformtrisazine, $N, N$-diformylhydrazine, and hexamethylenetetramine have been used in combustion reactions as high temperature flame fuels [13]. Compared to the above methods, the microwave method has the advantages of cost-effectiveness, low processing temperature, shorter reaction time, and high purity and homogeneity of the final product [14].

Currently, there is a growing need to develop the synthesis of environmentally benign nano-materials that are free from toxic chemicals in the synthesis. Hence, biosynthetic methods employing plant extracts have drawn attention as a simple and viable alternative to chemical procedures. Bioremediation of toxic metals that makes use of microorganisms such as bacteria, plant extracts, and yeast by detoxification occurs by the reduction of the metal ions/formation of metal oxides [15] These plants have been used in many medical applications and contains vitamins B1, B6, E, and A and also appreciable amounts of maleic, malonic, succinic, tartaric, and oxalic acid [16].

Nowadays, plant extracts have been used as both reducing and gelling agent for the synthesis of nano-materials [17]. The Opuntina dillenii haw plant extract is found mainly in the southern parts of India. Further determination of the sugars in the extract showed that $8 \%-10 \%$ of hexoses and $0.98 \%$ of pentoses are present. The major components of an Opuntia dilenii haw plant extract consist of a mixture of mucilage and pectin. Pectin is the most abundant polysaccharide from Opuntia dilenii haw. The plant extract plays not only a role as a fuel, but it also has a chemical coordinating action by capturing the involved metal ions in the amylose helix of the extract in well-defined sites and impeding the separation of $\mathrm{ZnAl}_{2} \mathrm{O}_{4}$. The synthesis strategy described here provides a facile, environmentally benign and low cost approach for the synthesis of $\mathrm{ZnAl}_{2} \mathrm{O}_{4}$ spinel. There has been a report on $\mathrm{ZnAl}_{2} \mathrm{O}_{4}$ nanosized particles prepared by using sucrose as a chelating agent [18] Therefore, sucrose should also act as an effective agent to prepare nanosized particles of $\mathrm{ZnAl}_{2} \mathrm{O}_{4}$.

Synthesis using the Opuntia dilenii haw extract provides a simple, efficient, and green route for the synthesis of nanosized materials. The slow reduction along with the shape-directing effects of the constituents of the Opuntia dilenii haw extract plays a key role in the formation of nanosized structured metal oxides $[19,20]$. Ongoing efforts are devoted to improving soft chemical methods, which are considered efficient routes, to tailor the sizes and shapes of the nanosized metal oxide. An appealing aspect of this research field is the non-polluting and controlled synthesis of oxide materials at low cost and using natural compounds as raw materials and also as the active ingredients in the formation of nanosized metal oxide particles. A facile, cheap, and green approach is provided in the present study for the synthesis of $\mathrm{ZnAl}_{2} \mathrm{O}_{4}$, which is a simple, fast, and economical combustion method using a plant extract, and it affords nanosized metal oxides with tunable sizes and morphologies.

In the present work, we report for the first time the synthesis of nanosized $\mathrm{ZnAl}_{2} \mathrm{O}_{4}$ by a microwave method using metal nitrates and an Opuntia dilenii haw (O. dilenii haw) plant extract solution as the precursors. The prepared nanosized materials were characterized by X-ray diffraction (XRD), Fourier transform infrared spectroscopy (FT-IR), high resolution scanning electron microscopy (HRSEM), energy dispersive X-ray analysis (EDX), diffuse reflectance spectroscopy (DRS), and photoluminescence (PL) spectroscopy. $\mathrm{ZnAl}_{2} \mathrm{O}_{4}$ samples prepared by the conventional and the microwave heating method both with and without using the plant extract were tested for their catalytic activity for the oxidation of benzyl alcohol.

\section{Experimental}

\subsection{Preparation of Opuntia dilenii haw plant extract}

Four grams of thoroughly washed Opuntia dilenii haw leaves (collected from local agricultural fields in Chennai, Tamil Nadu) were finely cut, and the gel obtained was dissolved in $12 \mathrm{ml}$ of deionized water and stirred for $45 \mathrm{~min}$ to obtain a clear solution. The resulting extract was used as the Opuntia dilenii haw plant extract solution.

\subsection{Preparation of $\mathrm{ZnAl}_{2} \mathrm{O}_{4}$ by conventional ( $\mathrm{CH}$ ) and microwave heating (MH) methods}

$\mathrm{Zn}\left(\mathrm{NO}_{3}\right)_{2}$ (99\%, Merck Chemicals, India) and $\mathrm{Al}\left(\mathrm{NO}_{3}\right)_{3}$ (98\%, Merck Chemicals, India) were dissolved in deionized water and then mixed with the Opuntia dilenii haw extract solution under constant stirring for $5 \mathrm{~h}$ at room temperature until a clear transparent solution was obtained. The molar ratio of $\mathrm{Zn} / \mathrm{Al}$ was kept at 1:2. The solution was dried in an air oven at $120{ }^{\circ} \mathrm{C}$ for $3 \mathrm{~h}$. The powders were then sintered at $400{ }^{\circ} \mathrm{C}$ at a heating rate of $5{ }^{\circ} \mathrm{C} / \mathrm{min}$ for $3 \mathrm{~h}$ in a muffle furnace and the sample obtained was labeled as $\mathrm{ZnAC}_{1}$ (prepared by conventional heating).

The above clear transparent solution was placed in a domestic microwave oven $(2.45 \mathrm{GHz}, 800 \mathrm{~W})$ for $10 \mathrm{~min}$. Initially, the solution boiled and underwent dehydration followed by decomposition with the evolution of gases. This vaporized the solution and it left behind a solid, which was labeled as $\mathrm{ZnAM}_{1}$ (prepared by microwave heating).

For comparison purpose, the $\mathrm{ZnAl}_{2} \mathrm{O}_{4}$ samples were also prepared without using the plant extract by both conventional and microwave heating and were labeled as $\mathrm{ZnAC}_{2}$ and $\mathrm{ZnAM}_{2}$, respectively. By using the microwave, a temperature of $400{ }^{\circ} \mathrm{C}$ was created inside the oven [21], and hence no pretreatment was necessary for the microwave treated samples. From the XRD, FT-IR, and EDX results, it was confirmed that only the $\mathrm{ZnAl}_{2} \mathrm{O}_{4}$ phase was formed without any other impurity, which in turn also confirmed the complete removal of the template for the microwave treated sample.

Metal nitrate salts and the plant extract (used in the mixture) were chosen by considering the total reducing and oxidizing agent valences of the raw materials. These were quantified in equivalence of $\mathrm{NO}_{x}$ reduction $\left(\mathrm{N}_{2} \mathrm{O}\right.$ to $\left.\mathrm{N}_{2}\right)$. At low temperatures and as a pure phase, fully crystallized $\mathrm{ZnAl}_{2} \mathrm{O}_{4}$ was obtained from both the compositions during the microwave method without the need for further calcination at higher tem- 
perature. This is due to the fact that the heating mechanism in a microwave oven is fundamentally different from the heating in a conventional furnace. Thermal conduction in the conventional furnace takes place through radiation and the convectional heating is by the transfer of thermal energy to inside the sample. However, microwave heating involves the absorption of the microwave field followed by the conversion of electromagnetic energy into the thermal energy. In this technique, there is no thermal conduction process involved. The heat is generated internally within the sample [22].

\subsection{Characterization of $\mathrm{ZnAl}_{2} \mathrm{O}_{4}$ nanosized structures}

The structural studies were carried out using a Philips $\mathrm{X}^{\prime}$ pert diffractometer for $2 \theta=10^{\circ}-80^{\circ}$ using $\mathrm{Cu} K_{\alpha}$ radiation at $\lambda$ $=0.154 \mathrm{~nm}$. A Perkin Elmer infrared spectrophotometer was used for the determination of the surface functional groups. Morphological studies and EDX analysis were performed using a JOEL JSM6360 high resolution scanning electron microscope. The samples were coated with gold by a gold sputtering device for better visibility of the surface morphology. Electrical conductance was studied by making samples in pellet form employing a pressure of about $1 \mathrm{GPa}$ at room temperature. The measurements were made from 120 to $300{ }^{\circ} \mathrm{C}$ by the twoprobe method. The pellets were well polished, and the two surfaces of each pellet were coated with silver paste to ensure electrical contacts. The samples were electrically connected to a dc power supply and a Keithley 614 digital electrometer in series. The activation energy of the samples was calculated by using the Arrhenius expression $I=I_{0} \exp ^{-E a} / k T$, where $I$ is the current, $E_{\mathrm{a}}$ is the activation energy, $k$ is the Boltzmann constant, and $T$ is the temperature.

The thermopower or Seebeck coefficient of a material is a measure of the magnitude of an induced hermoelectric voltage in response to a temperature difference across that material. The p- or n-type semiconductivity of the composites was confirmed by measuring the thermoelectric force of the composites. The thermoelectric or Seebeck coefficient $(\theta)$ of the composites was calculated using the formula $\theta=\Delta E / \Delta T$, where $\Delta E$ is the thermo-emf produced across the sample due to the temperature difference $\Delta T$ [23].

The diffuse reflectance UV-Visible spectra (DRS) of the nanosized materials were recorded using a Cary100 UV-visible spectrophotometer. The emission properties were recorded using a Varian Cary Eclipse fluorescence spectrophotometer.

The $\mathrm{N}_{2}$ adsorption-desorption isotherms of the samples were measured using an automatic adsorption instrument (Quantachrome Quadrawin gas sorption analyzer) for the determination of surface area and total pore volume.

\subsection{Catalytic test}

The oxidation of benzyl alcohol was carried out in a batch reactor operated under atmospheric conditions. $\mathrm{H}_{2} \mathrm{O}_{2} \quad(10$ mmol) was added along with $1 \mathrm{~g}$ of the nanosized zinc aluminate $\left(\mathrm{ZnAC}_{1}, \mathrm{ZnAC}_{2}, \mathrm{ZnAM}_{1}\right.$, and $\left.\mathrm{ZnAM}_{2}\right)$. The contents were heated to $80{ }^{\circ} \mathrm{C}$ in an acetonitrile medium for $10 \mathrm{~h}$ in a three-necked round-bottom flask equipped with a reflux condenser and thermometer. The oxidized products after the catalytic reaction were collected and studied using an Agilent GC. The column used for the study was DB wax column (capillary column) of length $30 \mathrm{~mm}$, and He was used as the carrier gas.

\section{Results and discussion}

\subsection{XRD studies}

To study the crystallization process and for phase identification, powder XRD analyses were performed on the various $\mathrm{ZnAl}_{2} \mathrm{O}_{4}$ samples. As shown in Fig. 1, the absence of the characteristic peaks of $\mathrm{ZnAl}_{2} \mathrm{O}_{4}$ over $\mathrm{ZnAC}_{2}$ and $\mathrm{ZnAM}_{2}$ samples confirmed that the $\mathrm{ZnAl}_{2} \mathrm{O}_{4}$ phase was not formed, but $\mathrm{ZnAl}_{2} \mathrm{O}_{4}$ cubic phase was present in $\mathrm{ZnAC}_{1}$ and $\mathrm{ZnAM}_{1}$ catalysts.

The observed diffraction peaks over $\mathrm{ZnAC}_{1}$ samples at $2 \theta=$ $18.96^{\circ}, 31.21^{\circ}, 36.77^{\circ}, 44.35^{\circ}, 55.65^{\circ}, 59.34^{\circ}$, and $65.23^{\circ}$ are associated with the (111), (220), (311), (400), (422), (511), and (440) planes, respectively. These planes are associated with the $d$-spacing values of $4.67,2.86,2.44,2.02,1.63,1.55$, and $1.43 \AA$, respectively, which can be readily assigned to the cubic phase of $\mathrm{ZnAl}_{2} \mathrm{O}_{4}$ (JCPDS file no. 74-1138). No peak of any other phase was detected. Over $\mathrm{ZnAM}_{1}$ catalyst, the observed diffraction peaks at $2 \theta=19.23^{\circ}, 31.79^{\circ}, 36.78^{\circ}, 44.71^{\circ}, 55.01^{\circ}, 59.54^{\circ}$, and $65.16^{\circ}$ are associated with the (111), (220), (311), (400), (422), (511), and (440) planes, respectively. These planes are associated with $d$-spacing values of $4.66,2.85,2.43,2.02,1.65,1.55$, and $1.42 \AA$, respectively, which is assigned to the cubic phase of $\mathrm{ZnAl}_{2} \mathrm{O}_{4}$ (JCPDS file no. 71-0968).

Further observations revealed that both $\mathrm{ZnAC}_{1}$ and $\mathrm{ZnAM}_{1}$ prepared using the plant extract had sharp peaks, indicating good crystallinity. The diffraction peaks for $\mathrm{ZnAM}_{1}$ were slightly broadened due to the smaller crystallite size, which may be due to the fact that $\mathrm{ZnAl}_{2} \mathrm{O}_{4}$ was prepared in a short time of 10 min by means of a domestic microwave oven operated at $2.45 \mathrm{GHz}$ and $800 \mathrm{~W}$ without any post-annealing. Furthermore, no other crystalline diffraction peaks were present in the XRD pattern, indicating the formation of highly pure $\mathrm{ZnAl}_{2} \mathrm{O}_{4}$. The average crystallite sizes for $\mathrm{ZnAC}_{1}$ and $\mathrm{ZnAM}_{1}$ calculated using Scherrer formula were 7.4 and $6.2 \mathrm{~nm}$, respec-

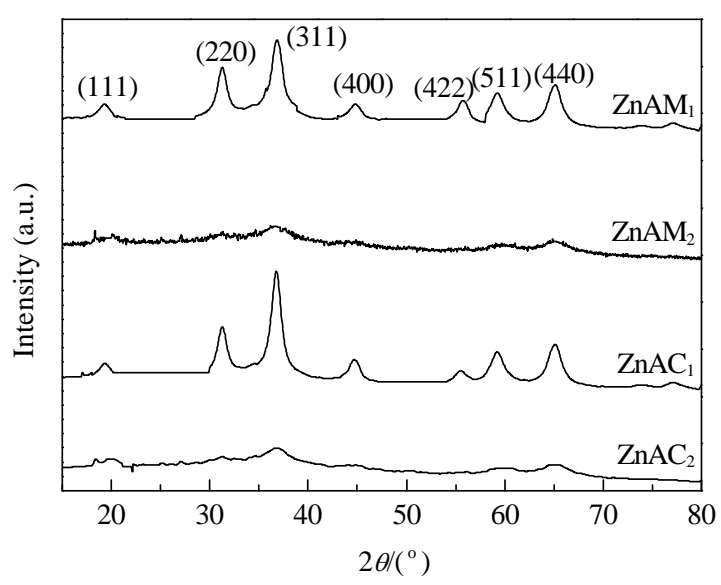

Fig. 1. XRD patterns of various $\mathrm{ZnAl}_{2} \mathrm{O}_{4}$ samples. 
tively. Thus by using the microwave method, the average crystallite size of the nanosized zinc aluminate was reduced.

\subsection{FT-IR results}

Figure 2 shows the FT-IR spectra of different $\mathrm{ZnAl}_{2} \mathrm{O}_{4}$ samples. The characteristic spinel bands of $\mathrm{ZnAl}_{2} \mathrm{O}_{4}$ were not observed over $\mathrm{ZnAC}_{2}$ and $\mathrm{ZnAM}_{2}$. This confirmed the absence of the formation of $\mathrm{ZnAl}_{2} \mathrm{O}_{4}$. However, $\mathrm{ZnAC}_{1}$ and $\mathrm{ZnAM}_{1}$ samples exhibited a common broad band near 3500 and $1600 \mathrm{~cm}^{-1}$, which is due to the $-\mathrm{OH}$ stretching vibrations and deformative vibration of water molecules. A broad band at $3465 \mathrm{~cm}^{-1}$ can be attributed to the stretching vibration of $-\mathrm{OH}$ groups in the brucite-like layers and interlamellar water molecules. The broadening of the band was attributed to hydrogen bond formation The band observed near $1643 \mathrm{~cm}^{-1}$ was assigned to the bending vibration of interlayer water molecules [25], which was probably due to the water absorption by the samples during the compaction of the powder specimen with $\mathrm{KBr}$ [26].

The spectra of all the samples showed a peak at $1300 \mathrm{~cm}^{-1}$ assigned to the Al-0 stretching vibration. The metal-oxygen stretching frequencies in the range $400-1000 \mathrm{~cm}^{-1}$ are related to the nanosized $\mathrm{ZnAl}_{2} \mathrm{O}_{4}$ [27]. The absorption peaks of $\mathrm{ZnAC}_{1}$ underwent a red shift for $\mathrm{H}_{2} \mathrm{O}$ (from 3505 to $3495 \mathrm{~cm}^{-1}$ and from 1634 to $1630 \mathrm{~cm}^{-1}$ ) and became weaker compared with $\mathrm{ZnAM}_{1}$, indicating a reduction in the degree of binding of $\mathrm{H}_{2} \mathrm{O}$ on the surface of larger crystallites, which was due to less atoms/surface for binding with $\mathrm{H}_{2} \mathrm{O}$ molecules $[27,28]$.

The metal oxygen stretching frequencies in the range of 500-900 $\mathrm{cm}^{-1}$ are associated with the vibrations of aluminum-oxygen and metal-oxygen-aluminum bonds for $\mathrm{ZnAC}_{1}$ and $\mathrm{ZnAM}_{1}$. Two sharp bands observed at 924 and $525 \mathrm{~cm}^{-1}$ are characteristic of $\mathrm{ZnAl}_{2} \mathrm{O}_{4}$ spinels. Thus, it was confirmed that for $\mathrm{ZnAl}_{2} \mathrm{O}_{4}$ formation, plant extract is needed during the preparation from the nitrate mixture using urea as the fuel.

\subsection{HR-SEM studies}

The morphologies of the nanosized $\mathrm{ZnAl}_{2} \mathrm{O}_{4}$ samples were investigated by HR-SEM. Figure $3(a, b)$ shows the formation of nanosized plates for $\mathrm{ZnAC}_{1}$, and Fig. $3(\mathrm{c}, \mathrm{d})$ shows the for-

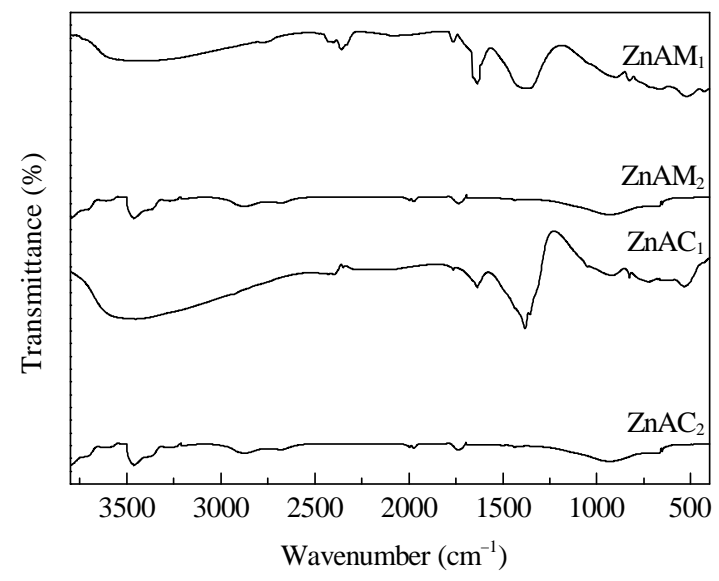

Fig. 2. FT-IR spectra of various $\mathrm{ZnAl}_{2} \mathrm{O}_{4}$ samples.

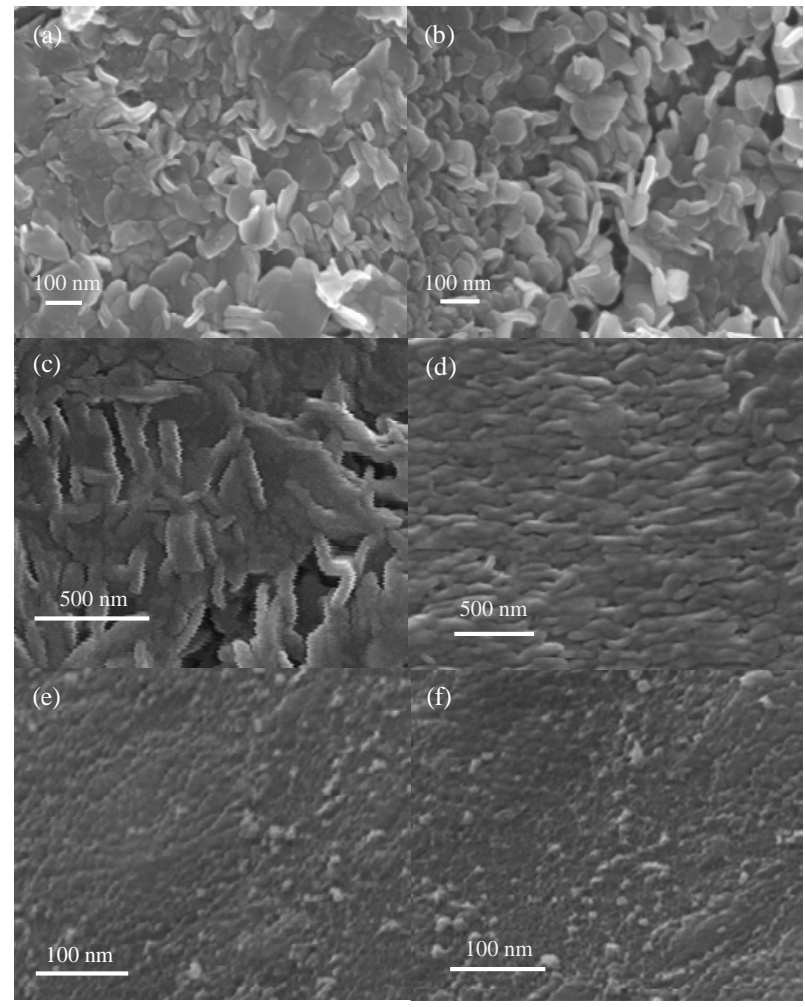

Fig. 3. HR-SEM images of $\mathrm{ZnAl}_{2} \mathrm{O}_{4}$ samples. (a, b) $\mathrm{ZnAC}_{1}$; (c, d) $\mathrm{ZnAM}_{1}$; (e) $\mathrm{ZnAC}_{2}$; (f) $\mathrm{ZnAM}_{2}$.

mation of nanosized sheets for ZnAM1. Thus, it is clear that the morphology and nanosized structures can be varied based on the method of preparation [29]. In the present study, the change in morphology from nanosized plates to nanosized sheets was obtained by changing the method of preparation from conventional to microwave heating. Figure 3(e, f) shows the HRSEM images of $\mathrm{ZnAC}_{2}$ and $\mathrm{ZnAM}_{2}$, which clearly showed that there was no defined or specific morphology formed, and hence it confirmed the absence of $\mathrm{ZnAl}_{2} \mathrm{O}_{4}$ phase formation.

In the case of $\mathrm{ZnAM}_{1}$, the hot spots formed due to the microwave irradiation of the powder surface stimulate particle aggregation in specific preferential directions to form the nanosized sheets morphology. Generally, in a conventional heating system, energy is transmitted to the constituents from the surface through convection, conduction, and radiation of heat. In contrast, in a microwave heating system, there is heating inside the materials, which then spreads to the surface [30,31]. Zinc aluminate is an excellent microwave adsorptive material and hence it readily heats up to the desired temperature much faster than in the conventional heating method. The observed slight difference in particle size value as estimated from XRD and HRSEM may be due to some structural disorder and strain in the lattice that resulted from the different ionic radii and/or clustering of the nanosized materials [32].

The presence of pure $\mathrm{ZnAl}_{2} \mathrm{O}_{4}$ was confirmed by EDX shown in Fig. 4. It showed that both $\mathrm{ZnAC}_{1}$ and $\mathrm{ZnAM}_{1}$ prepared by conventional and microwave heating, respectively, were composed of $\mathrm{Zn}, \mathrm{Al}$, and $\mathrm{O}$, indicating the presence of the pure $\mathrm{ZnAl}_{2} \mathrm{O}_{4}$ phase without any other impurity, in agreement with the XRD analysis. The peaks at 2.1-2.2 keV in the EDX spectra 


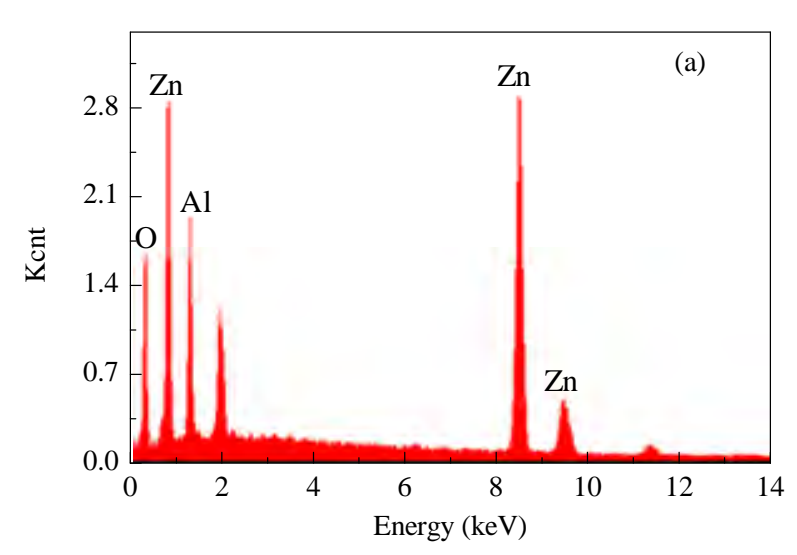

Fig. 4. EDX spectra of ZnAC1

were due to gold, which was coated on the samples before recording the SEM image.

\subsection{Electrical conductance studies}

To test the ohmic contact of the electrodes, room temperature electrical conductance measurements of the samples were carried out. The temperature dependence of electrical conductance carried out in the temperature range $120-300{ }^{\circ} \mathrm{C}$ suggested that the current increased with the increase in temperature (T). From the Arrhenius plot of $\ln \left(I / I_{0}\right)$ vs $1 / T$, the activation energy was calculated to be $0.24 \mathrm{eV}$ for $\mathrm{ZnAC}_{1}$ and $0.21 \mathrm{eV}$ for $\mathrm{ZnAM}_{1}$. The result also confirmed that the samples were semiconductors. The activation energy for electrical conduction in polycrystalline materials generally involves the combination of the energy required to raise the carriers from the dominant levels to their corresponding transport bands and the energy required to create the carriers from the dominant levels [33].

\subsection{Thermoelectric power (TEP) measurements}

The potential difference $\Delta V$ across the pelleted sample due to a temperature difference $\Delta T$ was measured. The cations on the A site as well as those on the B site contribute to the Seebeck coefficient, which showed n-type conduction for both the samples where the electrons are the majority charge carriers .

\subsection{DRS studies}

The optical diffuse-reflectance spectral properties of the prepared nanosized $\mathrm{ZnAl}_{2} \mathrm{O}_{4}$ samples were studied by DRS. As shown in Fig. 5, over $\mathrm{ZnAC}_{2}$ and $\mathrm{ZnAM}_{2}$ prepared without plant extract there was no optical absorption edge observed, indicating the absence of the formation of $\mathrm{ZnAl}_{2} \mathrm{O}_{4}$. As for $\mathrm{ZnAC}_{1}$ and $\mathrm{ZnAM}_{1}$ samples, the maximum reflectance of $98 \%$ was observed in the range of $290-520 \mathrm{~nm}$ due to absorption by the $\mathrm{ZnAl}_{2} \mathrm{O}_{4}$ nanosized material. DRS gives the direct band to band (valance band to conduction band) transitions from which the band gap can be calculated. For analysis purposes, the diffuse-reflectance $(R)$ of the sample $[34,35]$ can be related to

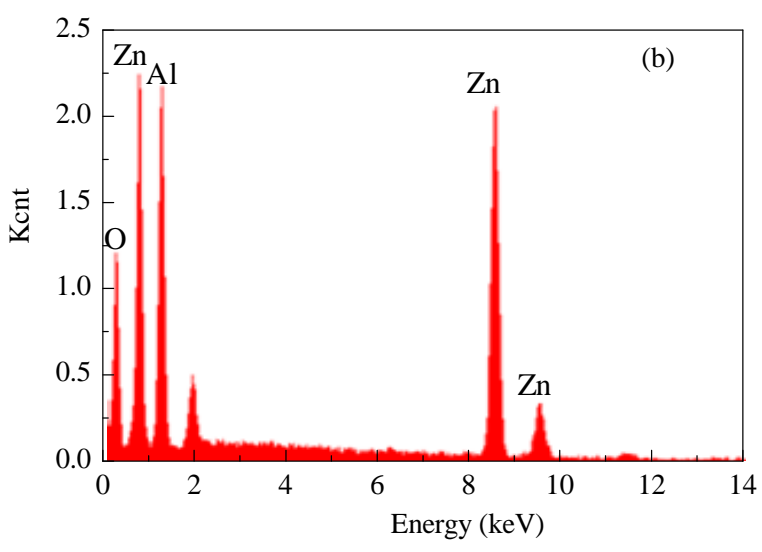

(a) and ZnAM1 (b) samples.

Kubelka-Munk function $F(R)$ by the relation $F(R)=(1-R)^{2} / 2 R$.

The energy intercept of a plot of $(F(R) \times h v){ }^{2}$ versus $h v$ gives $E_{\mathrm{g}}$ for a direct allowed transition when the linear region is extrapolated to the zero ordinate. The optical absorption edge was observed at a wavelength of $380 \mathrm{~nm}$, which corresponds to the band gap energy of $3.5 \mathrm{eV}$ for $\mathrm{ZnAC}_{1}$. The observed band gap energy of the $\mathrm{ZnAM}_{1}$ was $3.9 \mathrm{eV}$ corresponding to a wavelength of $360 \mathrm{~nm}$. These results showed that the band gap energy of $\mathrm{ZnAl}_{2} \mathrm{O}_{4}$ prepared by the microwave method using the plant extract had shifted to a higher energy value. This increase in the band gap may be associated with the decrease in oxygen content due to the microwave heating.

\subsection{PL studies}

A photoluminescence spectrum is used to determine defect related transitions and oxygen vacancies. The density of defects and surface states may change with the formation conditions, morphology, and size of the crystallites. It is therefore interesting to examine the different defect energy levels. As shown in Fig. 6, $\mathrm{ZnAC}_{2}$ and $\mathrm{ZnAM}_{2}$ prepared without the plant extract do not show any significant emission peak, thus showing the absence of formation of $\mathrm{ZnAl}_{2} \mathrm{O}_{4}$. For $\mathrm{ZnAC}_{1}$ and $\mathrm{ZnAM}_{1}$ samples prepared using the plant extract, emission peaks were observed at $\sim 482,528$, and $540 \mathrm{~nm}$, which were due to in-

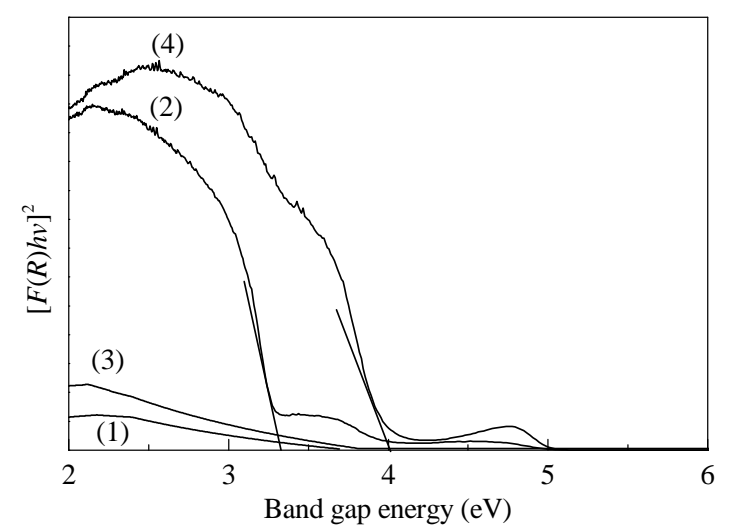

Fig. 5. Diffuse reflectance spectra of $\mathrm{ZnAl}_{2} \mathrm{O}_{4}$ samples. (1) $\mathrm{ZnAC}_{2}$; (2) $\mathrm{ZnAC}_{1}$; (3) ZnAM $\mathrm{Zn}_{2}$ (4) ZnAM . 


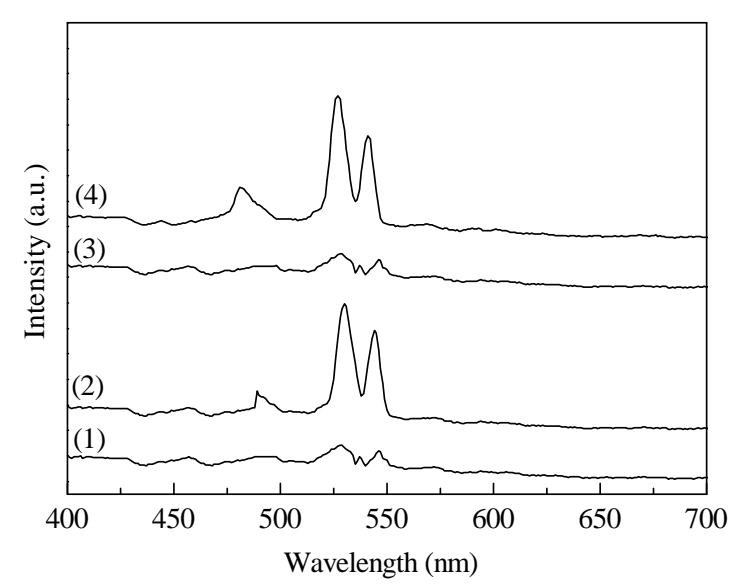

Fig. 6. Photoluminescence spectra of $\mathrm{ZnAC}_{2}$ (1), $\mathrm{ZnAC}_{1}$ (2), $\mathrm{ZnAM}_{2}$ (3), and $\mathrm{ZnAM}_{1}(4)$ samples.

tra-band gap defects like oxygen vacancies. These defects provide donor levels near the conduction band edge of the zinc aluminates. However, the emission peaks were considerably blue shifted to 492,530 , and $545 \mathrm{~nm}$ for $\mathrm{ZnAM}_{1}$ due to the reduction in the average crystallite size, which was in good agreement with the XRD data. The wavelength of $\mathrm{ZnAM}_{1}$ was longer (blue shift more) than that of $\mathrm{ZnAC}_{1}$ because of the reduction in the crystallite size $\left(\mathrm{ZnAC}_{1} 7.4 \mathrm{~nm}\right.$ and $\mathrm{ZnAM}_{1} 6.2$ $\mathrm{nm}$ ), which in turn is responsible for quantum confinement effect [36].

There was a significant increase in the intensity of the signal at 530 and $545 \mathrm{~nm}$ for $\mathrm{ZnAM}_{1}$. This may be due to an increase in the surface defect sites of $\mathrm{ZnAl}_{2} \mathrm{O}_{4}$. During microwave heating, heat is generated internally within the material instead of originating from external heating sources, and hence an inverted temperature gradient is produced. The interionic distance between the two species is the determining factor for the efficiency of the observed energy transfer process. The emission spectra of both $\mathrm{ZnAC}_{1}$ and $\mathrm{ZnAM}_{1}$ also showed emission peaks between 480 and $540 \mathrm{~nm}$ generated by the lattice host $\mathrm{ZnAl}_{2} \mathrm{O}_{4}[37,38]$.

\section{8. $\quad N_{2}$ adsorption isotherms}

The $\mathrm{N}_{2}$ adsorption isotherm values at $-196^{\circ} \mathrm{C}$ for $\mathrm{ZnAC}_{1}$ and $\mathrm{ZnAM}_{1}$ are given in Table 1. The $\mathrm{ZnAC}_{1}$ sample possessed a surface area of $41.87 \mathrm{~m}^{2} / \mathrm{g}$, whereas for $\mathrm{ZnAM}_{1}$, it was increased considerably to $66.54 \mathrm{~m}^{2} / \mathrm{g}$. The pore volume of $\mathrm{ZnAC}_{1}$ and $\mathrm{ZnAM}_{1}$ were 0.16 and $0.12 \mathrm{~cm}^{3} / \mathrm{g}$, respectively. Similarly, the average pore diameter of $\mathrm{ZnAM}_{1}$ was increased to $97.33 \AA$, but for $\mathrm{ZnAC}_{1}$, it was only $94.19 \AA$ A During the reaction process, molecular dipoles were induced to oscillate by the microwave.

Table 1

BET surface area, average pore diameter, and pore volume of $\mathrm{ZnAl}_{2} \mathrm{O}_{4}$ samples prepared using the plant extract.

\begin{tabular}{lccc}
\hline Sample & $\begin{array}{c}\text { BET surface area } \\
\left(\mathrm{m}^{2} / \mathrm{g}\right)\end{array}$ & $\begin{array}{c}\text { Average pore diame- } \\
\text { ter }(\AA)\end{array}$ & $\begin{array}{c}\text { Pore volume } \\
\left(\mathrm{cm}^{3} / \mathrm{g}\right)\end{array}$ \\
\hline ZnAC1 & 41.87 & 94.19 & 0.16 \\
ZnAM1 & 66.54 & 97.33 & 0.12 \\
\hline
\end{tabular}

The oscillation caused a higher rate of molecular collision, which in turn generated more heat. Therefore, the temperature distribution was homogeneous and transferred to the material's interior, leading to an explosion reaction followed by the vigorous evolution of gases to form nanosized zinc aluminates. Also, during the microwave process, the heating is usually achieved within a few minutes, which gives rapid phase formation and a fine particle size. Also, in microwave synthesis, the reaction time is short and the equipment is not complex, making this technique very attractive. Therefore, it is possible to control both kinetic and thermodynamic factors of the chemical reactions using microwave in the combustion process. Hence, this microwave method offers several advantages like forming a chemically homogeneous composition, simple reaction process, low energy loss, inexpensive, nontoxic, high production efficiency and high purity products [39].

\subsection{Catalytic oxidation of benzyl alcohol}

The catalytic oxidation of benzyl alcohol was studied using $\mathrm{ZnAl}_{2} \mathrm{O}_{4}$ nanosized plates and nanosized sheets to investigate its performance as a catalyst. One gram of prepared nanosized $\mathrm{ZnAC}_{1}$ and $\mathrm{ZnAM}_{1}$ along with the oxidant $\mathrm{H}_{2} \mathrm{O}_{2}(10 \mathrm{mmol})$ in an acetonitrile medium was placed in a batch reactor. The contents were heated at $80^{\circ} \mathrm{C}$ for $10 \mathrm{~h}$. When the oxidized product was analyzed using $\mathrm{GC}$, the conversion of benzyl alcohol reached a maximum of $85 \%$ for $\mathrm{ZnAM}_{1}$, whereas for $\mathrm{ZnAC}_{1}$, the conversion was only $60 \%$ with $100 \%$ selectivity. In our previous studies, we have reported the preparation of nanosized copper aluminate spinel by a modified sol-gel method using ethylenediamine, in which the conversion of benzyl alcohol to benzaldehyde was $100 \%$ [40]. In the present work, Opuntia dilenii haw plant extract was used to prepare nanosized $\mathrm{ZnAl}_{2} \mathrm{O}_{4}$, and the performance of the $\mathrm{ZnAl}_{2} \mathrm{O}_{4}$ catalysts were compared with those of the earlier catalysts [41-43] in Table 2. The result showed that the present $\mathrm{ZnAl}_{2} \mathrm{O}_{4}$ catalyst gave a higher yield with good selectivity for benzaldehyde as compared to the previous ones. Also, the method of preparation in the present study is very simple and economic.

Table 2

Comparison of the catalysts prepared in the present study with those reported in the literature for oxidation of benzyl alcohol.

\begin{tabular}{|c|c|c|}
\hline Catalyst & $\begin{array}{c}\text { Conversion } \\
(\%)\end{array}$ & $\begin{array}{c}\text { Selectivity } \\
(\%)\end{array}$ \\
\hline$\overline{\mathrm{ZnAC}_{1}}$ & 60.0 & 100 \\
\hline $\mathrm{ZnAM}_{1}$ & 85.0 & 100 \\
\hline \multirow[t]{3}{*}[\mathrm{Cu}((\mathrm{Benzyl}){}_{2}\mathrm{Bzo}_{2}[14]\mathrm{aneN6})]{$^{2+}-\mathrm{NaY}^{\mathrm{a}}[41]$} & 74.5 & 100 \\
\hline & 75.7 & 100 \\
\hline & 74.2 & 100 \\
\hline \multirow[t]{3}{*}[\mathrm{Cu}(\mathrm{Me}_{4}(\mathrm{NO}_{2})_{2}\mathrm{Bzo}[14]\text{tetraeneN}{}_{4})]{$-\mathrm{NaY}^{\mathrm{a}}[42]$} & 82.3 & 100 \\
\hline & 83.1 & 100 \\
\hline & 81.0 & 100 \\
\hline \multirow[t]{3}{*}[\mathrm{Cu}(\mathrm{Me}_{4}[16]\mathrm{aneN}_{8})]{$\left(\mathrm{ClO}_{4}\right)_{2}$ a $[43]$} & 53.5 & 92 \\
\hline & 56.5 & 98 \\
\hline & 50.1 & 95 \\
\hline
\end{tabular}

a Conditions: benzyl alcohol $5 \mathrm{ml}$, benzene $10 \mathrm{ml}, \mathrm{H}_{2} \mathrm{O}_{2}$ /benzyl alcohol (molar ratio) $=2,70{ }^{\circ} \mathrm{C}, 10 \mathrm{~h}$, and the concentrations were determined using internal standard procedure. 
Table 3

Effect of oxidant and catalyst on the catalytic oxidation of benzyl alcohol.

\begin{tabular}{lccc}
\hline Entry & Catalyst & Oxidant & Yield (\%) \\
\hline 1 & $\mathrm{ZnAC}_{1}$ & - & 3.0 \\
2 & $\mathrm{ZnAM}_{1}$ & - & 4.5 \\
3 & - & $\mathrm{H}_{2} \mathrm{O}_{2}$ & 2.5 \\
4 & $\mathrm{HnAC}_{2}$ & $\mathrm{H}_{2} \mathrm{O}_{2}$ & 0.8 \\
5 & $\mathrm{ZnAM}_{2}$ & $\mathrm{H}_{2} \mathrm{O}_{2}$ & 1.0 \\
\hline
\end{tabular}

Reaction conditions: catalyst $\mathrm{ZnAl}_{2} \mathrm{O}_{4} 1 \mathrm{~g}$, benzyl alcohol $10 \mathrm{mmol}$, acetonitrile $10 \mathrm{mmol}, \mathrm{H}_{2} \mathrm{O}_{2} 10 \mathrm{mmol}, 80^{\circ} \mathrm{C}, 10 \mathrm{~h}$.

In the absence of the oxidant, $\mathrm{ZnAC}_{1}$ showed $3.0 \%$ yield of benzaldehyde, and $\mathrm{ZnAM}_{1}$ showed $4.5 \%$ of yield (Table 3 ). In the absence of a catalyst, only $2.5 \%$ yield of benzaldehyde was obtained using the oxidant $\mathrm{H}_{2} \mathrm{O}_{2}$. Thus, it was confirmed that both the catalyst and the oxidant were important to give high yield. The samples prepared without the plant extract gave very low yields of benzaldehyde, i.e., $\mathrm{ZnAC}_{2}$ and $\mathrm{ZnAM}_{2}$ gave only $0.8 \%$ and $1.0 \%$ of benzaldehyde as the product. Hence, the plant extract is important in forming the nanosized $\mathrm{ZnAl}_{2} \mathrm{O}_{4}$ phase, which in turn is active for the catalytic oxidation reaction.

A comparison of the data also indicated the differences between the three complexes and the zinc aluminate and their performance in the benzyl alcohol-to-benzaldehyde oxidation. Transition metal complexes always exhibit low activity and selectivity. They are also difficult to separate from the reaction medium, which makes their reuse difficult, and it contaminates the reaction products. A heterogeneous catalyst like zinc aluminate is non-toxic and environmentally friendly and has excellent catalytic performance.

\subsection{Reusability studies}

The reusability performance of $\mathrm{ZnAC}_{1}$ and $\mathrm{ZnAM}_{1}$ for 5 cycles of batch oxidation reaction is illustrated in Fig. 10. After the catalytic reaction, $\mathrm{ZnAC}_{1}$ or $\mathrm{ZnAM}_{1}$ was filtered and washed

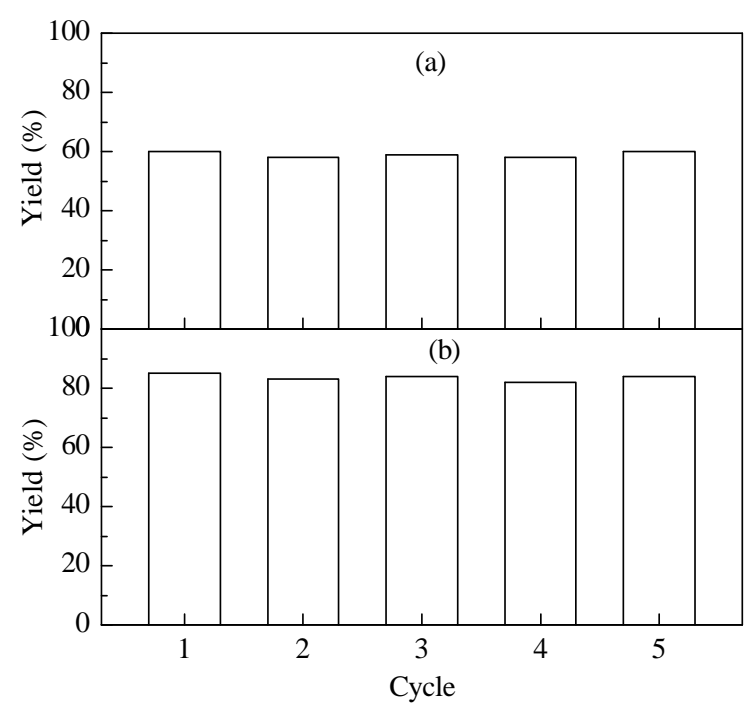

Fig. 10. Reusability of $\mathrm{ZnAC}_{1}$ (a) and $\mathrm{ZnAM}_{1}$ (b) catalysts in the oxidation of benzyl alcohol. with ethanol several times, then dried at $120^{\circ} \mathrm{C}$ in an air for $4 \mathrm{~h}$ to remove the ethanol. It was used for five consecutive runs under identical conditions. In these runs, the conversions and selectivities remained at almost the similar level to that of the first run. $\mathrm{ZnAl}_{2} \mathrm{O}_{4}$ was found to have no appreciable loss of activity in the recycle tests. Thus, it was proved that the catalyst has a stable structure during the catalysis.

\section{Conclusions}

Zinc aluminate spinel samples were prepared using conventional heating $\left(\mathrm{ZnAC}_{1}\right)$ and microwave heating $\left(\mathrm{ZnAM}_{1}\right)$ using an Opuntia dilenii haw extract solution and compared with the $\mathrm{ZnAC}_{2}$ and $\mathrm{ZnAM}_{2}$ prepared without using the plant extract. Microwave heating achieved the same results within a shorter time compared to the conventional heating method. The average crystallite size for $\mathrm{ZnAC}_{1}$ and $\mathrm{ZnAM}_{1}$ prepared using the plant extract was 7.4 and $6.2 \mathrm{~nm}$, respectively. The formation of the $\mathrm{ZnAl}_{2} \mathrm{O}_{4}$ phase was confirmed by XRD, SEM, and FT-IR results. The room temperature electrical conductivity studies confirmed that the prepared nanosized zinc aluminates are semiconductors. The activation energy was 0.24 and $0.21 \mathrm{eV}$ for $\mathrm{ZnAC}_{1}$ and $\mathrm{ZnAM}_{1}$, respectively. TEP results showed that both the samples exhibit n-type conduction with electrons as the major charge carriers. Absorption bands in the visible region showed band gap values of 3.5 and $3.9 \mathrm{eV}$, respectively, for $\mathrm{ZnAC}_{1}$ and $\mathrm{ZnAM}_{1}$. The nanosized zinc aluminates were used as a catalyst for the conversion of benzyl alcohol with a conversion efficiency of $60 \%$ for $\mathrm{ZnAC}_{1}$ and $85 \%$ for $\mathrm{ZnAM}_{1}$. Hence a simple, rapid bio-synthetic green method using Opuntia dilenii haw has been developed to synthesize $\mathrm{ZnAl}_{2} \mathrm{O}_{4}$ nanosized structures with tunable optical and better catalytic properties.

\section{References}

[1] Kim D K, Zhang Y, Kehr J, Klason T, Bjelke B, Muhammed M. J Magn Magn Mater, 2001, 225: 256

[2] O'Regan B, Gratzel M. Nature, 1991, 353: 737

[3] Stobbe E R, de Boer B A, Geus J W. Catal Today, 1999, 47: 161

[4] Tzing W S, Tuan W H. J Mater Sci Lett, 1996, 15: 1395

[5] Bouropoulos N, Tsiaoussis I, Poulopoulos P, Roditis P, Baskoutas S. Mater Lett, 2008, 62: 3533

[6] Kumar K, Ramamoorthy K, Koinkar P M, Chandramohan R, Sankaranarayanan K. J Nanoparticle Res, 2007, 9: 331

[7] Phani A R, Passacantando M, Santucci S. Mater Chem Phys, 2001, 68: 66

[8] Moreno E M, Zayat M, Morales M P, Serna C J, Roig A, Levy D. Langmuir, 2002, 18: 4972

[9] Valenzuela M A, Jacobs J P, Bosch P, Reijne S, Zapata B, Brongersma H H. Appl Catal A, 1997, 148: 315

[10] Valenzuela M A, Bosch P, Aguilar-Rios G, Montoya A, Schifter I. J Sol Gel Sci Technol, 1997, 8: 107

[11] Zawadzki M, Wrzyszcz J. Mater Res Bull, 2000, 35: 109

[12] Zou L, Li F, Xiang X, Evans D G, Duan X. Chem Mater, 2006, 18: 5852

[13] Dhak D, Pramanik P. J Am Ceram Soc, 2006, 89: 1014

[14] Manikandan A, Judith Vijaya J, John Kennedy L, Bououdina M. Ceram Int, 2013, 39: 5909

[15] Mann S. Nature, 1993, 365: 499 


\section{Graphical Abstract}

Chin. J. Catal., 2013, 34: 1951-1958 doi: 10.1016/S1872-2067(12)60682-2

Catalytic properties of nanosized zinc aluminates prepared by green process using Opuntia dilenii haw plant extract

C. Ragupathi, J. Judith Vijaya*, S. Narayanan, L. John Kennedy,

Seeram Ramakrishna

Loyola College, India;

Vellore Institute of Technology University, India;

National University of Singapore, Singapore

$\mathrm{ZnAl}_{2} \mathrm{O}_{4}$ is prepared by using the Opuntia dilenii haw plant extract. Structural and optical properties are studied. Higher conversion and better selectivity for benzyl alcohol is achieved.

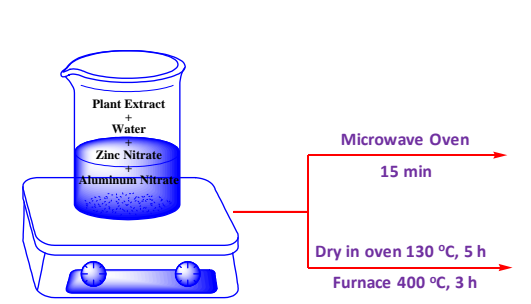

Microwave Method

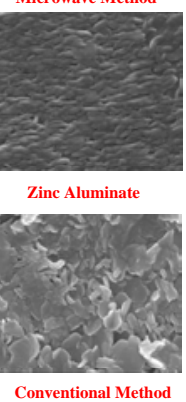

[16] Abd El-Razek F H, Hassan A A. Aust J Basic Appl Sci, 2011, 5: 356

[17] Galati E M, Pergolizzi S, Miceli N, Monforte M T, Tripodo M M. J Ethnopharmacol, 2002, 83: 229

[18] Khaledi A G, Afshar S, Jahromi H S. Mater Chem Phys, 2012, 135: 855

[19] Satoh E, Ishii T, Shimizu Y, Sawamura S-I, Nishimura M. Exp Biol Med, 2001, 226: 577

[20] Boubekri R, Beji Z, Elkabous K, Herbst F, Viau G, Ammar S, Fiévet F, von Bardeleben H J, Mauger A. Chem Mater, 2009, 21: 843

[21] Selvam N C S, Manikandan A, Kennedy L J, Vijaya J J. J Colloid Interface Sci, 2013, 389: 91

[22] Thomas P, Sathapathy L N, Dwarakanath K, Varma K B R. Bull Mater Sci, 2007, 30: 567

[23] Patil L A, Patil D R. Sens Actuators B, 2006, 120: 316

[24] Becheri A, Dürr M, Lo Nostro P, Baglioni P. J Nano particle Res, 2008, 10: 679

[25] Kloprogge J T, Frost R L. J Solid State Chem, 1999, 146: 506

[26] Vijaya J J, Kennedy L J, Sekaran G, Nagaraja K S. Mater Res Bull, 2008, 43: 473

[27] Foster M, Furse M, Passno D. Surf Sci, 2002, 502-503: 102

[28] Lu J S, Yang H B, Liu B B, Zou G T. Mater Res Bull, 1999, 34: 2109

[29] He Y J. Mater Lett, 2006, 60: 3511
[30] Ortega Y, Fernández P, Piqueras J. J Cryst Growth, 2009, 311: 3231

[31] Thostenson E T, Chou T W. Composites Part A, 1999, 30: 1055

[32] Serpone N, Lawless D, Khairutdinov R. J Phys Chem, 1995, 99: 16646

[33] Manikandan A, Judith Vijaya J, John Kennedy L, Bououdina M. J Mol Struct, 2013, 1035: 332

[34] Sundaram R, Raj E S, Nagaraja K S. Sens Actuators B, 2004, 99: 350

[35] Amaranatha Reddy D, Murali G, Vijayalakshmi R P, Reddy B K, Sreedhar B. Cryst Res Technol, 2011, 46: 731

[36] Liu J Y, Lu Y M, Liu J, Yang X Y, Yu X B. J Alloys Compd, 2010, 496: 261

[37] Hao Y F, Meng G W, Ye C H, Zhang X R, Zhang L D. J Phys Chem B, 2005, 109: 11204

[38] Barros B S, Melo P S, Kiminami R H G A, Costa A C F M, Sá G F, Alves S Jr. J Mater Sci, 2006, 41: 4744

[39] Monticone S, Tufeu R, Kanaev A V.J Phys Chem B, 1998, 102: 2854

[40] Kumar R T, Suresh P, Selvam N C S, Kennedy L J, Vijaya J J. J Alloys Compd, 2012, $522: 39$

[41] Salavati-Niasari M, Davar F. Inorg Chem Commun, 2006, 9: 304

[42] Salavati-Niasari M. J Mol Catal A, 2006, 245: 192

[43] Salavati-Niasari M, Ganjali M R, Norouzi P. Transition Met Chem, 2007, 32: 1 